University of New Mexico

UNM Digital Repository

3-9-1989

\title{
Non-Fisherian sex ratios with sex change and environmental sex determination.
}

Eric Charnov

J.J. Bull

Follow this and additional works at: https://digitalrepository.unm.edu/biol_fsp

Part of the Biology Commons

\section{Recommended Citation}

Nature 338:148-150

This Article is brought to you for free and open access by the Academic Department Resources at UNM Digital Repository. It has been accepted for inclusion in Biology Faculty \& Staff Publications by an authorized administrator of UNM Digital Repository. For more information, please contact disc@unm.edu. 
TABLE 2 Aluminium and silicon levels in fish from experimental treatment tanks

\begin{tabular}{ccc}
\hline Tank & $\begin{array}{c}\text { Aluminium } \\
\text { ( } \mu \text { mol per } 8 \text { dry mass) }\end{array}$ & $\begin{array}{c}\text { Silicon } \\
\text { ( } \mu \mathrm{mol} \text { per } 8 \text { dry mass) }\end{array}$ \\
1 (control) & $0.44[0.22]^{*}$ & $0.01[0.02]$ \\
2 & $0.40[0.11]$ & $0.54[0.26]$ \\
3 & $2.04[0.43]$ & $0.35[0.14]$ \\
4 & $2.49[0.79]$ & $0.33[0.14]$ \\
5 & $2.38[1.24]$ & $0.08[0.04]$ \\
\hline
\end{tabular}

The results are from three independent experimental runs. Three fish were removed from each tank every $12 \mathrm{~h}$ : moribund fish from tanks 3,4 and 5 , and healthy fish from tanks 1 and 2 . These fish were lightly rinsed in dilute $\mathrm{HNO}_{3}$ to remove superficial aluminium on the skin before digestion in concentrated $\mathrm{HNO}_{3}$. The rinse did not remove aluminium from the gill and served to reduce variability in the aluminium level measurement. Analysis for aluminium and silicon was by atomic absorption spectroscopy using a graphite furnace.

* Values are means with standard deviation shown in brackets.

$\mathrm{Ca}^{2+}$ or $\mathrm{Mg}^{2+}$ below $\mathrm{pH} 10$, aluminium is removed from competition with these ions and with $\mathrm{Na}^{+}$for binding at gill surfaces.

We conclude that the $\mathrm{Si}$ : Al balance in acid waters is a key, hitherto neglected, factor affecting the bioavailability and toxicity of aluminium. Increasing the level of silicic acid may be as significant as raising the $\mathrm{pH}$ in alleviating the toxic effect of aluminium. A general question arises from this conclusion. Silicon has been claimed to be essential for the normal development of higher animals ${ }^{16,17}$; is silicon intrinsically an essential element for growth or does it merely limit the bioavailability of aluminium (in the mammalian gut, for example) as a result of the formation of hydroxy-aluminosilicates ${ }^{18}$ ?

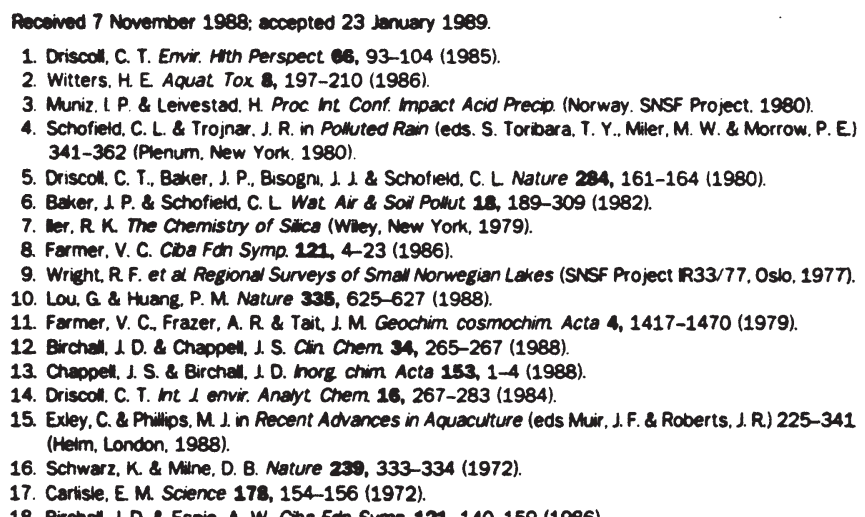

18. Birchal L D. \& Espie. A. W. Cba Fon Symp. 121, 140-159 (1986).

ACKNOWLDGEMENTS. We thank ICI Chemicals and Polymer Group for their support of this study and in particular for supporting the postgraduate work of C.E.

\section{Non-fisherian sex ratios with sex change and environmental sex determination}

\section{Eric L. Charnov* \& J. J. Bull†}

\author{
* Department of Biology, University of Utah, Salt Lake City, \\ Utah 84112, USA \\ †Department of Zoology, University of Texas, Austin, Texas 78712, USA
}

FISHER'S theory of sex-ratio evolution' explains why $1: 1$ sex ratios are so prevalent ${ }^{2-8}$. Recent work has therefore emphasized situations in which biased sex ratios tend to evolve (for example, local mate competition? ${ }^{7}$ non-mendelian inheritance of sex-ratio factors ${ }^{7,9,10}$, haplodiploid social insects ${ }^{11,12}$ and others ${ }^{6,13}$ ). In species where individuals change sex during their adult lifetimes, and in species where sex is determined by environmental conditions experienced during pre-adult development, biased sex ratios are expected and frequently observed ${ }^{6}$. Sex-ratio models for particular kinds of sex change (SC) and environmental sex determination (ESD) have predicted excesses of the first sex ${ }^{6,14,15}$ under $S C$, and of the sex developing in the 'worse' environment under ESD ${ }^{6.14-16}$. Here we generalize and unite these results in a single model that applies to a wide range of SC and ESD biologies. The principle that emerges from this model appears to explain strong female and male excesses seen in sex-changing fish and invertebrates and in nematodes with ESD. It is not known whether the female excess commonly seen in reptiles with ESD are also explained by this principle.

We develop this principle for sex change. Let the continuous variable $t$ indicate an individual's age, $\phi(t)$ the probability of surviving to age $t, m(t)$ the immediate fertility of a male at age $t$, and $f(t)$ the immediate fertility of a female at age $t$. The lifetime male fertility $[\chi(\tau)]$ of individuals who become male first and change sex at age $\tau$ is then

$$
\chi(\tau)=\int_{0}^{\tau} m(t) \phi(t) d t
$$

and lifetime fertility as female is

$$
y(\tau)=\int_{\tau}^{\infty} f(t) \phi(t) \mathrm{d} t
$$

(ref.6). The fertilities $m(t)$ and $f(t)$ may be thought of as relative fitnesses: $m(t)$ is the average fitness of a male at age $t$ divided by the fitness of an arbitrarily-chosen standard male, and similarly for $f(t)$; because of this scaling, $m(t)$ and $f(t)$ as well as $\chi(\tau)$ and $y(\tau)$ do not measure absolute fitness because they do not depend on sex ratio. Note that, in the definitions of $\chi(\tau)$ and $y(\tau)$, mortality and age/sex-specific fertility are functions of age but are not directly functions of $\tau$, the time of sex change. More complicated models for the evolution of sex change allow $\phi(t), f(t)$ and $m(t)$ to depend on $\tau$ (refs 6,17 ), but these additional complications do not alter the basic results from this simpler model, as will be presented here (see Fig. 1).

Models of sex-allocation theory typically consider the fate of a rare mutation adopting one sex-allocation strategy $\left(\tau^{\prime}\right)$ in a population of individuals who otherwise adopt a different strategy $(\tau)$. The common genotype resists invasion provided that the net effect of the mutation on male plus female fitness is negative ${ }^{6}$, that is, if

$$
\frac{\int_{0}^{\tau^{\prime}} m(t) \phi(t) \mathrm{d} t}{\int_{0}^{\tau} m(t) \phi(t) \mathrm{d} t}+\frac{\int_{\tau^{\prime}}^{\infty} f(t) \phi(t) \mathrm{d} t}{\int_{\tau}^{\infty} f(t) \phi(t) \mathrm{d} t}<2
$$

A common genotype whose sex-allocation strategy cannot be invaded by any alternative strategy is said to be evolutionarily stable $^{2}$. The evolutionarily stable equilibrium for sex change must satisfy the principle that an individual's immediate fitness is independent of whether it is male of female ${ }^{6}$ : if the population instead adopted a $\tau$ for which fitness at age $\tau$ was greater through one sex than the other, selection would favour altering $\tau$ to extend the sex phase with higher reproductive success. To calculate the appropriate fitnesses, we may let female fitness at age $t$ be proportional to fertility, $c_{1} f(t)$. Male fitness will also be proportional to fertility, but in addition it must be scaled by the sex ratio: recalling Fisher's' sex-ratio argument, if adult males are half as common as adult females, the average number of children per male will be twice that per female. Male fertility must therefore be multiplied by $c_{1} \int_{\tau}^{\infty} f(t) \phi(t) \mathrm{d} t / \int_{0}^{\tau} m(t) \phi(t) \mathrm{d} t$ 
FG. 1 A generalized sex-ratio theory for sex change. Assuming protandry (male first), male lifetime fertility $[X(\tau)]$ is plotted versus female lifetime fertility $[y(\tau)]$ for $0 \leqslant \tau \leqslant \infty$. Unlike in the text, here we allow the functions $m(\cdot), f(\cdot)$, and $\phi(\cdot)$ to depend on $\tau$ as well as on $t$ Such generalizations would apply, for example, if growth rate or death rate depended on sex. For protandry to be evolutionarily stable (uninvasible by protogyny or dicecy), this curve must be bowed outward, as drawn ${ }^{6.23}$. The evolutionarily stable value of $\tau$ can be shown ${ }^{8}$ to maximize $x(\tau) \cdot y(\tau)$. At this maximum, $\partial y / \partial x=-y / x$,

$$
\left|\frac{\partial y}{y}\right|=\left|\frac{\partial x}{x}\right| \text {. }
$$

From this generalized version of equation (3), It follows that

$$
\frac{r}{1-r}=\frac{\bar{F} /|\partial y|}{\bar{M} /|\partial x|}
$$

The ratio of males to females $[r /(1-r)]$ is thus the inverse ratio of normalized averase sex-specific fertlities. It is not obvious that this generalized sex-ratio result implies an excess of the first sex (at equilibrium), but this direction of sex-ratio excess is present in all of the cases we have studied, provided that male and female fertilities increase with age/size.

to yield male fitness. Equivalence of male and female fitness at the evolutionarily stable age of sex change, $\hat{\gamma}$, therefore requires

$$
\frac{m(\hat{\tau})}{\int_{0}^{f} m(t) \phi(t) d t}=\frac{f(\hat{\tau})}{\int_{f}^{\infty} f(t) \phi(t) d t}
$$

A simple relation between sex ratio and average fertility follows immediately from (3). The left-hand denominator may be written as $k \cdot r \cdot \bar{M}$, where $k=\int_{0}^{\infty} \phi(t) \mathrm{d} t, r$ is the adult sex ratio, $\int_{0}^{T} \phi(t) d t / k$ and $\bar{M}$ is the average male fertility, $\int_{0}^{r} m(t) \phi(t) d t / k r$. The right-hand denominator may likewise be written as $k \cdot(1-r) \cdot \bar{F}$, where $\bar{F}$ is the average female fertility. With this notation in mind, (3) may be written as

$$
\frac{r}{1-r}=\frac{F / f(\hat{\tau})}{\bar{M} / m(\hat{\tau})}
$$

The evolutionarily stable adult sex ratio, $r$, is thus seen to depend on the average fertility of males relative to the fertility of a $\hat{\tau}$-age male, and on the average fertility of females relative to the fertility of a $\hat{\tau}$-age female. The adult sex ratio favours the sex experiencing the lower fertility values, where fertility is measured relative to a $\hat{\tau}$-age individual of the same sex. Of course, equation (4) applies to protogyny as well as protandry.

Result 4 is substantially more general than indicated by the present model. It applies whether age, size or some other combi-

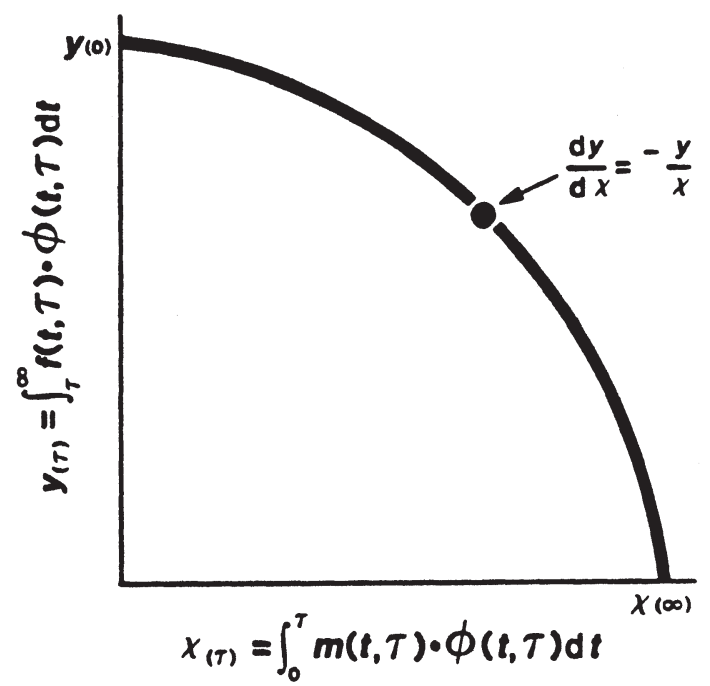

nation of traits is used to trigger sex change. More generally, the form of equation 4 applies even if male and female fertilities or mortality depend on sexual experience (developed in Fig. 1). Result 4 is only approximately true if individuals suffer a temporary decrease in fertility during sexual transition ${ }^{17-19}$, but the error is trivial if the decrease in fertility applies to only a brief part of the second sexual phase. Result 4 is not robust to high levels of mortality incurred during sexual transition, although mortality immediately after sexual transition is incorporated. There is, however, no evidence for any high mortality cost during sex transition, at least in fish ${ }^{17-19}$. Finally, result 4 applies to environmental sex determination, with sex determined in response to the environmental cue $t$ either by the parent ${ }^{20,21}$ or by the offspring ${ }^{6,14,15,20} ; m(t)$ is then the expected lifetime fertility of a male raised at $t, f(t)$ is the expected lifetime fertility of a female, and $\hat{\tau}$ defines the conditions for which a male and a female have the same expected lifetime fitness. In this latter application, $r$ is the evolutionarily stable primary sex ratio. Thus, this theory applies to the Trivers-Willard model of parentcontrolled $\mathrm{ESD}^{20}$.

Adult sex ratios estimated for protogynous fish and protandrous invertebrates are typically skewed, sometimes toward males and other times toward females. However, sex change occurs in two basic forms: protandry (male function first in life)

\begin{tabular}{|c|c|c|}
\hline Taxonomic group and bcation & Proportion male & Ref. \\
\hline \multicolumn{3}{|l|}{ Protendry (male first) } \\
\hline Pandalid shrimp (several species, Northern Hemisphere)* & $0.55-0.75$ & 23,24 \\
\hline Patella vulgata (limpet, UK) & 0.75 & 25 \\
\hline Crepidula (limpet, North America) $\dagger$ & & \\
\hline C. fornicata (6 locations or years) & $0.4(1), 0.5-0.75(5)$ & 26 \\
\hline C. convexa (3 locations) & $0.35-0.6$ & 26 \\
\hline Amphiprion (anemonefish, several species and locations) & 0.5 & 33,34 \\
\hline \multicolumn{3}{|l|}{ Protosyny (female first) } \\
\hline Scaridae (Parrotfish 3 sp., Caribbean) $\ddagger$ & $0.15,0.23,0.26$ & 27 \\
\hline (3 species, E. Australia) $\ddagger$ & $0.21,0.33,0.38$ & 28 \\
\hline Labridae (wrasses 2 sp., Caribbean) $\ddagger$ & $0.11,0.24$ & 29 \\
\hline Labroides (cleaner wrasse, Australia) & 0.15 & 30 \\
\hline Epinephelus (red grouper, Florida) & 0.17 & 31 \\
\hline Anthias (many locations) & 0.1 or less & 32 \\
\hline Centropyge (anglefish, Japan) & 0.29 & 35 \\
\hline
\end{tabular}
and protogyny (female first). From sex-allocation theory, protandry is evolutionarily stable if female fertility increases with

TABLE 1 Sex ratios in sequential hermaphrodites

* Estimates were obtained from adult mortality and sex-change data.

+ Both species show a positive correlation between sex ratio and population density.

¥ Some species exhibit a pure male morph as well as the sequential hermaphroditic morph; sex-ratio data were included here only if at least $98 \%$ of the population was of the hermaphroditic morph. 
age faster than does male fertility, that is, if the ratio $f(t) / m(t)$ increáses monotonically with age; protogyny is evolutionarily stable if this ratio decreases ${ }^{6,17,18}$. Female fertility may often be determined by fecundity and should increase with age. Male fertility may also usually increase with age, but the extent of this increase will depend on the social system. The greatest potential for an increase in $m(t)$ with $t$ should be associated with extreme polygyny, hence we expect that protogyny will be associated with polygyny. Protandry, on the other hand, should be found in species in which single males do not monopolize many matings.

If fertility increases with age for both sexes, a protandrous male should be most fit just before changing sex whereas a protandrous female is least fit just after changing sex, so

$$
\frac{\bar{M}}{m(\tau)}<1<\frac{\bar{F}}{f(\tau)}
$$

From results 4 and 5 we expect a male excess under protandry, and a male excess is nearly always observed (Table 1). Under protogyny, these inequalities should be reversed, and the expected female excess is also supported by the data. The obvious alternative hypothesis-that the second sex is rarer because the brief period of sexual transition involves high mortality-finds no support in observations on sex change in fish ${ }^{17-19}$.

Several of the protogynous fish listed in Table 1 exhibit social systems in which a few males dominate a social group and appear to prevent females from changing sex. Removal of a male leads to rapid sex change of the largest or most dominant female ${ }^{19}$. Such systems are easily incorporated into the foregoing framework, except that fertility is a discrete rather than continuous function of group size. Equality 3 then becomes an inequality, and the sex-ratio skew will be even greater than predicted by equation 4 . Anemonefish (whose observed sex ratio is 0.5 ) provide a special case because the social system limits group size to two individuals, in which case male fertility depends entirely on group composition, not age. The limpet Crepidula convexa also violates the usual protandry sex-ratio pattern; the reason for this exception is unexplained but may stem from the mobility of males, which may offer an advantage to small size $[m(t)$ would decrease with $t]$.

Sex ratios under environmental sex determination are also skewed from 0.5 , favouring males in a mermithid nematode ${ }^{22}$ and females in reptiles (data were summarized in ref. 8). A mermithid's sex is determined in response to nutrition during its juvenile phase when it parasitizes an insect: a worm developing in an undernourished, crowded, and or/small host becomes a male, whereas a worm developing in a large, well-nourished host becomes a female ${ }^{6,22}$. The mermithid case thus parallels protandry. The primary sex ratio lies in the range $0.7-0.9$ for each of five populations of the mosquito parasite Romanomermis nielseni, which is remarkable in view of the fact that the distributions of $t$ differ greatly among populations ${ }^{22}$.

Data from a variety of turtles and crocodilians with temperature-dependent sex determination suggest that primary sex ratios are often as extreme as $\mathbf{0 . 3}$, although the sex ratio in some species is consistent with 0.5 (ref. 8). These skewed sex ratios fall within the range observed in sex-changing fish and mermithids, but it is not yet plausible that incubation temperature has such large effects on fertility ${ }^{21}$.

The present theory offers the best explanation for overall trends in the data in that the direction of observed sex-ratio excesses are predicted (except in Crepidula). The observed sexratio excesses are often extreme, particularly under protogyny and in the nematodes. The present theory can potentially account for the observed magnitudes of deviations from 0.5 , but quantitative predictions await studies of the actual fertility functions, $m(t)$ and $f(t)$. Perhaps the most interesting aspect of this theory as applied to sex change is that the generalizations apply to the adult or breeding sex ratio. Under typical fisherian sex-ratio selection for dioecious species, it is the primary sex ratio that is predicted to obey a generalization (equal investment), and the adult sex ratio is simply a consequence of the prevailing sex-specific mortality rates.
Roceived 21 November 1988; cocepted 31 lenuery 1989.

1. Fisher, R. A. The Genetical Theary of Nwturd Sabction (Clerendon, Oxford. 1930).

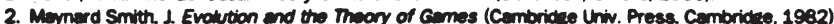

3. Shaw, R. F. Mohier. J. D. Am. Net e7, 337-342 (1953).

4. Whiams, G. C. Adaptation and Notural Selection (Princeton Univ. Press, Princeton, 1966).

5. Leigh, E. G Oxford Surveys eval Biod 2, 187-223 (1986).

6. Chernov, E. L. The Theory of Sex Alocetion (Princeton Univ. Press, Princeton, 1982).

7. Hemiton. W. D. Saince 158, $477-488$ (1967).

8. Bull, J. J. \& Charnov, E. L Oxford Surveys avol Bid 8, 96-135 (1988).

9. Lewis, D. New Phrtatogist 40, 56-63 (1941).

10. Howard H. W. \& Canet

11. Hemition. W. D. A. Aev. Ecol Syst \& 193-232 (1972)

12. Trivers, R. L. \& Hare, H. H. Science 191, 249-263 (1976).

13. Kartin, S. Lessard, S. Theoretical Studies on Sex Ratio Evolution (Princeton Univ. Press, Princeton, 1986).

14. Frenk, S. A. \& Swingand, L. S. \& theor. Bid 128, 415-418 (1988)

15. Chernov, E. L. \& Bull, \& \&. \& theor. Bial (in the press).

16. Bull, J. J. Heredity 4h, 8-26 (1981).

17. Warner, R. R. Envirommentel Biology of Fishes Vol. 22, 81-90 (1988)

18. Warner, R. R. Trends Ecol. Evol. 3, 133-136 (1988).

19. Shepiro, D. Y. Saince 200, 1136-1137 (1980).

20. Trwors, R. L. \& Wilerd, D. E. Scionce 179, 90-92 (1973).

21. Bull, J. J. Evolution of Sex Determinin Mecheniems (Benjemin/Cummines, Menio Perk, 1983).

22. Blackmore, M. S. thesis, Univ. Utin (1989).

23. Chernov, E. L. Am. Net 113, 715-734 (1979).

24. Charnov. E. L., Gotshel, D. \& Robinson, J. Science 200, 204-206 (1978).

25. Batentine, W. L. thesis, London Univ. (1961)

26. Hoedend, K. E. Malscologio 17, 365-391 (1978).

27. Robertson. D. R. \& Werner, R. R. Smithsonien Contrit. Zool $285,1-26$ (1978).

28. Chost, I H. \& Robertson, D. R. in intersexulity in the Anima Kinedom (ed. Reinboth, R.) 263-283 (Springer, Bertin, 1975).

29. Warner, R. R. \& Robertson, D. R. Smithsonien Contrth. Zool 224, 1-27 (1978).

30. Pobertson, D. R. \& Chost, J. H. Proc Socond int Symp. Cord Poef's 1 (Biolog), 217-225 (1974).

31. Moe, M. A. Forida Dept Nat Resources Prof. Paper 10, 1-95 (1969).

32. Sheopro. D. Y. \& Lubbock, R. \& theor. Biol $12,411-426$ (1980)

33. Fricke, H. F Fricke, S. Noture $203830-832$ (1977).

34. Fricke, H. W. Z Tierpsychad sa, 313-326 (1979).

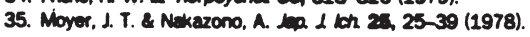

\section{Production of chimaeric mice containing embryonic stem (ES) cells carrying a homoeobox Hox 1.1 allele mutated by homologous recombination}

\section{Andreas Zimmer \& Peter Gruss}

Max-Planck Institut für biophysikalische Chemie, Abt Molekulare Zellbiologie, Am Fassberg, 3400 Göttingen, FRG

SEveral mouse gene families related to Drosophila developmental control genes and containing a homoeobox, a paired box or a finger domain, have been cloned and structurally analysed. On the basis of structural similarities to the Drosophila genes and of their spatially and temporally restricted expression patterns during mouse embryogenesis, it has been proposed that these mammalian genes also are involved in the control of development $^{1-4}$. To elucidate the function of homoeobox genes by genetic means, mouse mutants must be generated. We have developed a technique for mutagenesis in vivo and have used it to mutate the homoeobox Hox 1.1 gene. In vivo mutagenesis was achieved through homologous recombination between an endogenous Hox 1.1 allele and a microinjected mutated gene in pluripotent embryonic stem (ES) cells ${ }^{5-9}$. Mutant cells were identified by means of the polymerase chain reaction (PCR) ${ }^{10}$ and mutant clones were used to generate chimaeric mice. Because the homologous recombination event is formally a gene conversion event and no selection is required to screen for cells carrying the mutated allele, in vivo mutagenesis allows specific alterations in the target sequence to be made without the introduction of any other sequences. 